\title{
QUALIDADE DA DEMOCRACIA E INTERESSE POPULAR POR SINDICATOS E GREVES - UM ESTUDO COMPARADO DE 114 PAÍSES (2004-2014)
}

\author{
QUALITY OF DEMOCRACY AND POPULAR INTEREST FOR UNIONS \\ AND STRIKES - A COMPARATIVE STUDY OF \\ 114 COUNTRIES (2004-2014)
}

Thiago Perez Bernardes de Moraes ${ }^{1}$ e Romer Mottinha Santos ${ }^{2}$

Recebido em: 26/05/2014

Aprovado em: 15/09/2015

\section{RESUMO}

Historicamente, os sindicatos constituem um importante meio para a representação dos trabalhadores e para a consolidação da democracia. Mas será que esses órgãos ainda são representativos em um cenário de constante tendência de perda de força? Para responder a essa pergunta, traçamos duas hipóteses: 1) nos países onde o interesse popular por sindicatos e greves é mais alto, é maior a qualidade da democracia; 2) separadamente, onde o interesse por sindicatos é mais alto, é maior a qualidade da democracia, mas o mesmo não deve se repetir em localidades onde é maior o interesse por greves. Ao compararmos a média total quanto à distribuição geográfica do interesse por greves e sindicatos, constatamos uma significativa correlação que indica que o interesse por sindicatos é maior em países mais democráticos. Todavia, ao comparar separadamente a distribuição do interesse por greves e sindicatos com a qualidade da democracia, constatamos que há uma forte correlação entre o interesse por greves e a democracia, o que não se repete quanto ao interesse por sindicatos. Podemos afirmar, ainda, que um índice de $5 \%$ da distribuição da qualidade da democracia é impulsionado pelo interesse popular por sindicatos. Isso confirma nossa segunda hipótese, podendo indicar, também, que os sindicatos estão adotando outras estratégias além das greves, motivo pelo qual é possível inferir que os sindicatos vão "sobreviver" à tendência atual de perda de densidade.

Palavras-chave: Sindicatos; Greve; Democracia; Google Trends.

\begin{abstract}
Historically the unions represent an important means for the representation of workers and for the consolidation of democracy. But I wonder if he's still a constant scenario representative tendency to loss of density? To answer this question we make two assumptions: 1) in countries where the popular interest for unions and strikes is highest, is the greater the quality of democracy; 2) separately, where the interested unions is highest, is the greater the quality of democracy but the same should not be repeated with locations where greater interest by strikes. Comparing the total average regarding geographical distribution of interest by strikes and unions, we found a significant correlation indicating that the interest in unions is greater in more democratic countries. However, we compare separately the distribution of interest by strikes and unions with the quality of democracy, noted that compared to the first a strong correlation, but the same is not repeated in the second. We can say that $5 \%$ of the distribution of the quality of democracy is driven by the popular interest in unions. This confirms our second hypothesis, which may indicate that the unions are adopting other strategies in addition to the strikes, which is why it is possible to infer that the unions will "survive" the current trend of loss of density.
\end{abstract}

Keywords: Trade unions; Strikes; Democracy; Google Trends.

\footnotetext{
' Doutor em Psicologia Social pela Universidad Argentina John Fitzgerald Kennedy (UAJFK), Argentina. Professor no Centro Universitário Campos de Andrade (UNIANDRADE). E-mail: thiagomoraessp@hotmail.com.

${ }^{2}$ Mestre em Ciência Política pela Universidade Federal do Paraná (UFPR), Brasil. E-mail: romermottinha@gmail.com.
} 


\section{Introdução}

Historicamente, os sindicatos constituem não só um meio eficiente de representação dos trabalhadores, mas também um instrumento para a consolidação da democracia. Tanto como promovedor de negociações coletivas quanto como agente da militância industrial, os sindicatos, desde o começo do século XX até os dias atuais, são atores pivôs na política e na sociedade. Entretanto, com as mudanças estruturais promovidas pelo capitalismo, os sindicatos do mundo assistem a uma vertiginosa queda quanto ao número de sindicalizados, o que em larga medida compromete as possibilidades de exercício de representação por parte dos sindicatos. Neste cenário, será que os sindicatos ainda conseguem promover uma representação suficiente a ponto de influenciar a qualidade da democracia?

A hipótese deste estudo é a de que, em países onde o interesse por sindicatos e por greves trabalhistas é maior, a qualidade da democracia tende a ser mais alta. Tal hipótese se baseia na constatação de que, onde o interesse por sindicatos e greves é maior, a força do sindicato também é mais elevada, o que favorece uma representação mais eficiente, fato este que pode alterar de forma positiva a qualidade da democracia. Outra hipótese é a de que, possivelmente, apenas o interesse por sindicatos tenha alta correlação com a qualidade da democracia, uma vez que a alta frequência do tópico greve seja mais comum em países com menor qualidade democrática, que são aqueles onde as desigualdades estruturais se manifestam com mais força.

Para testar estas hipóteses, traçamos no Google Trends frequências de interesse do tipo Beta para os tópicos relacionados aos sindicatos e às greves. Consideramos como recorte temporal o período de janeiro de 2004 a março de 2014 e como recorte espacial o montante de 114 países. Utilizamos, também, dados do The Democracy Ranking ofthe Quality of Democracy de 2008 a 2012, desenvolvidos pelo The Democracy Ranking Association, referentes à qualidade da democracia em 114 países.

\section{Sindicatos e representação do inte- resse comum}

Para Olson (1999), a ideia de que os grupos sempre agem para promover seus interesses é supostamente fundamentada na premissa de que os membros de um grupo agem por interesse pessoal. Todavia, não é verdade que a ideia de que os grupos agirão para atingir seus objetivos seja uma sequência lógica da premissa do comportamento racional e centrado nos próprios interesses. Mesmo que todos os indivíduos de um grupo grande sejam racionais e centrados nos próprios interesses e que saiam ganhando se, como grupo, agirem para atingir seus objetivos comuns, ainda assim eles não agirão voluntariamente para promover esses interesses comuns ou grupais (Olson, 1999, p. 14). Segundo Tsebelis (1998, p. 33), a racionalidade nada mais é que uma correspondência ótima entre fins e meios.

Um propósito que, de fato, é característico da maioria das organizações, principalmente daquelas com um aspecto econômico marcante, consiste na promoção dos interesses de seus membros. É pertinente perceber que os interesses que todos esses tipos de organizações supostamente devem promover são, em sua maioria, interesses comuns. Além disso, é possível supor que os indivíduos que pertencem a uma organização ou a um grupo têm um interesse comum, assim como interesses puramente individuais, diferentes dos interesses dos outros membros do mesmo grupo (Olson, 1999, p. 18-20).

Nesta nossa era de grandes negócios e grandes mercados de trabalho, a maioria dos sindicatos constitui grandes organizações. No entanto, nem sempre foi assim. Os primeiros sindicatos 
eram organizações pequenas e locais, característica que não se alterou por um longo período. O movimento sindical norte-americano, por exemplo, iniciou com uma série de pequenos sindicatos independentes uns dos outros, cada qual com seus interesses locais, de forma que o desenvolvimento dos sindicatos nacionais viáveis nos Estados Unidos teve início mais de meio século depois de terem surgido os sindicatos locais. Mesmo depois que os sindicatos nacionais tinham se estabelecido, passou-se algum tempo até que estes tomassem o posto dos sindicatos locais como principal manifestação de força trabalhista (Olson, 1999, p. 79). Embora possam existir muitos fatores diferentes que ajudem a explicar esse padrão histórico do crescimento dos sindicatos, ele pode ser explicado, ao menos parcialmente, pelo fato de que os pequenos grupos podem se favorecer de benefícios coletivos melhor do que os grandes grupos (Olson, 1999, p. 80).

A negociação coletiva no último século representou um grande pivô em uma série de benesses sociais e, também, na consolidação da democracia. Historicamente $^{3}$, o sindicato foi uma útil ferramenta para a redução da desigualdade social, ocasionando a aquisição de garantias quanto a relações e condições de trabalho mais justas. Isso permite afirmar que os sindicatos não são atores meramente econômicos, constituindo, na verdade, pivôs da arena política. Ocorre que, nas últimas décadas, os sindicatos têm diminuído, em todo o mundo, no que se refere à densidade de sindicalizados ${ }^{4}$, o que, de forma direta, compromete o seu potencial de ação, sobretudo no que diz respeito a levar a cabo a negociação coletiva junto ao

${ }^{3}$ Durante o começo do século XX, houve, no mundo industrializado, uma grande explosão no que diz respeito à militância industrial e política, a qual agiu com força nas negociações, sobretudo com o uso da violência, o que fez com que o sindicalismo revolucionário ganhasse destaque e notoriedade, colocando uma série de líderes sindicais como players com grande poder de barganha. Tais líderes conseguiam mobilizar grandes greves em vários países (DARLINGTON, 2013).

${ }^{4}$ Densidade de sindicalizados diz respeito ao número total de trabalhadores sindicalizados em relação ao indice de não sindicalizados. Esse desinflar constante é observado na maioria dos países do mundo, especialmente nas últimas décadas. poder político em prol do sindicalizado (HAYTER, FASHOYIN, KOCHAN, 2011; ANDOLFATTO, LABBÉ, 2012; GUMBRELL-MCCORMICK, 2012).

Entretanto, mesmo com pouco poder de barganha em mãos, os sindicatos ${ }^{5}$, nos diversos lugares do mundo, continuam a desempenhar um papel importante na distribuição de benefícios e de contrapesos às disparidades estruturais. Exemplo disso é a amostra empírica que sugere que, na União Europeia, os sindicalizados que precisam utilizar o segurosaúde para o afastamento das atividades de trabalho são demitidos com menos frequência do que os não sindicalizados que também solicitam o auxílio-doença para o afastamento laboral. A evidência ${ }^{6}$ sugere que a maior flexibilidade quanto ao afastamento do trabalho e do uso do seguro-saúde constitui um ganho privado próprio das organizações sindicais europeias (GOERKE; PANNENBERG, 2012). Esse fato representa um epifenômeno das possibilidades de benefícios que os sindicatos podem, atualmente, conceber aos sindicalizados, mesmo gozando de baixo poder de barganha na maior parte do mundo.

A evidência indica, também, que os sindicatos podem facilitar o processo de contratação de longo prazo, gerando benefícios amplos no relacionamento entre empregador e empregado. Entretanto, é preciso considerar que, no cenário atual, em muitos países, os sindicatos não conseguem ou ainda não podem mais apoiar políticas de redistribuição de renda que visem reduzir a desigualdade salarial (ADDISON, 2013).

Historicamente, a evidência empírica advinda da análise de movimentos

\footnotetext{
${ }^{5}$ Não é possível para trabalhadores não organizados criar um grande sindicato, mesmo que eles estejam cientes da necessidade da coerção, já que têm de se organizar primeiro para terem então uma organização que possa impor a política do estabelecimento sindicalizado. Todavia, é possível para um pequeno sindicato emergir sem compulsão e, em seguida, tornar a afiliação a ele compulsória para assegurar sua sobrevivência e aumentar sua força (OLSON, 1999).

${ }^{6}$ Há também uma forte relação entre força dos sindicatos e melhores condições de segurança no trabalho. Considerando que a maioria das empresas, tradicionalmente, é contrária a dispendiosas adoções de práticas de segurança, os sindicatos desempenham um papel importante para a aquisição dessas práticas, o que garante em alguma medida a média de saúde dos trabalhadores e, consequentemente, a oferta de trabalho agregado (DONADO e WÄLDE, 2012).
} 
sindicalistas revolucionários na França, na Espanha, na Itália, na Irlanda, nos Estados Unidos e na Inglaterra sinalizam que tanto a iniciativa organizacional quanto a ideologia e a liderança dos sindicatos representam objetos de grande importância para a compreensão dos movimentos sindicais. Isso ocorre porque, em algum nível, os sindicatos foram e continuam a ser, de forma simultânea, uma causa contributiva, um sintoma e um beneficiário da militância dos trabalhadores (DARLINGTON, 2013).

O desafio dos sindicatos é, entretanto, em larga medida, multifatorial ${ }^{7}$, pois uma série de processos estruturais distintos tem elevado o desemprego ${ }^{8}$ e, não obstante, tem feito surgir novas formas de subcontratação e de flexibilização dos direitos trabalhistas. Indubitavelmente, um dos fenômenos protagonistas desse cenário é a privatização em nível global. Um estudo elencando dados sobre a privatização industrial sinaliza que ela pode ser associada a, pelo menos, $20 \%$ do aumento do desemprego e à redução dos salários e dos direitos trabalhistas. Nestes contextos onde as privatizações ganharam larga abrangência, os sindicatos tendem a ser mais fracos (AZMAT; MANNING; REENEN, 2012).

Como a porcentagem de sindicalizados cai em ritmo constante, é esperado que, concomitante a este processo, haja um retrocesso quanto à capacidade de mobilização popular dos sindicatos, sobretudo no que concerne a organizar greves trabalhistas. Frente à queda vertiginosa na densidade de sindicalizados em todo o mundo, os sindicatos têm um desafio difícil para reverter tal tendência.

\footnotetext{
7 "Em geral, as situações de representação política geram envolvimento simultâneo em vários jogos: no jogo parlamentar e no jogo eleitoral propriamente dito para os representantes no Congresso, em um jogo de barganha e num jogo entre o líder e as bases para os representantes do sindicato, num jogo na política internacional entre economia e política também pode ser conceituada com diversos jogos jogados pelos mesmos atores. De maneira geral, pode-se argumentar que as democracias contêm situações em quais os jogos não são jogados de maneira isolada e, portanto, as escolhas podem parecer sub ótimas" (TSEBELIS, 1998, p. 20-21). "De as escich to à o to à oferta de empregos em todo o mundo. Para compreender esse fato, deve-se considerar, dentre outros aspectos, o avanço da tecnologia que propiciou uma redução nos custos de produção, afetando de forma inevitável toda a estrutura macroeconômica da maioria dos países (KARABARBOUNIS e NEIMAN, 2013).
}

Entretanto, como o potencial de barganha e, consequentemente, a aquisição de benefícios para as classes trabalhistas são baixos, os sindicatos devem, antes de tudo, buscar adesão por parte da sociedade. Trata-se, assim, de "vender" a imagem dos sindicatos aos sindicalizados e, sobretudo, aos não sindicalizados. A evidência empírica sugere que o uso das redes sociais, como o Facebook, tem tido um saldo positivo no que diz respeito a atrair usuários ativos e, consequentemente, sindicalizados (BRYSON; GOMEZ; WILLMAN, 2010). Nesse sentido, torna-se vital um estudo sistemático dos vestígios digitais gerados nesta relação, o que inclui toda comunicação realizada em sites, blogs e redes sociais e também $o$ interesse manifesto dos internautas nos motores de busca.

\section{Método}

Neste trabalho, utilizamos o Google Trends ${ }^{9}$ para aferir a frequência espacial e temporal de interesse por termos relacionados aos sindicatos e às greves trabalhistas no período de 2004 a 2014 em um total de 40 semanas em 114 países. Utilizamos também dados do The Democracy Ranking of the Quality of Democracy ${ }^{10} \mathrm{de} 2008$ a 2012, desenvolvidos pelo The Democracy Ranking Association, referentes à qualidade da democracia em 114 países.

Selecionamos o Google Trends, pois ele é, certamente, o motor de busca reversa mais eficiente de toda a web (KUOET al., 2012; MORAES et al.,

\footnotetext{
${ }^{9}$ Em relação a outros métodos de coleta de dados próprios das Ciências Sociais, o Google Trendstraz pelo menos três vantagens sólidas: 1) possibilita pesquisas rápidas e gratuitas, com dados sempre atualizados; 2) oferece dados de praticamente todos os países do mundo; 3) permite download gratuito de todas as frequências, tendo em vista que apresenta um custo de pesquisa muito baixo (MELLON, 2013; MORAES, 2014). ${ }^{10} \mathrm{~A}$ medida do ranking de democracia tem o interesse em medir três dimensões da estrutura democrática: 1) liberdade; 2) igualdade; e 3) performance. Para isso, o ranking de democracia baseia-se em duas grandes dimensões: 1) liberdade e outras características do sistema político $(50 \%)$; e 2) desempenho de dimensões não políticas $(50 \%)$. Dentro do espectro não político, o ranking de democracia considera cinco pontos: 1) gênero (igualdade de gênero) $(10 \%) ; 2)$ economia (sistema econto (10\%); 3) col (10\%), (10\%); 4) sude (sade d poplaco e sivisa e acesso a inform ções) $(10 \%)$; 4) saúde (saúde da população e sistema de saúde) (10\%); 5) meio ambiente (sustentabilidade ambiental) $(10 \%)$. Para as diferentes dimensões, políticas e não políticas, uma larga gama de indicadores é atribuída, sendo todos transformados em uma frequência de 1 a 100, em que 1 representa o menor e 100 o maior (CAMPBELL, 2008).
} 
2014). Nesse sentido, enquanto um motor de busca tradicional apresenta uma relação de links para cada objeto pesquisado, o motor de busca reversa oferece uma lista relativa à distribuição no tempo e no espaço dos usuários que registraram suas preferências nos motores de busca (MORAES, MILLANI, 2014; MORAES, SANTOS, 2015).

O Google Trends apresenta a frequência com que um termo é procurado no Google, o motor de busca mais utilizado no mundo, dispondo de uma base de dados que permite verificar as regiões do mundo onde o termo foi buscado e o volume de pesquisas sobre um termo em determinado período. O download destes dados é livre e está disponível para praticamente todos os países. Em suma, o motor busca gera frequências espaciais e temporais para termos específicos e conjuntos de termos, as frequências do tipo Beta ${ }^{11}$. Tais frequências trazem valores úteis não só para a compreensão do modus operandi de uso da internet, mas, também, para a compreensão das variáveis independentes que afetam a realidade do mundo off-line (MORAES, SANTOS, 2013, MORAES, MAIA, 2014; FANTAZZINI, FOMICHEV, 2014).

\section{Resultados}

No Gráfico 1, exposto a seguir, consideramos duas frequências de interesse temporal medidas no Google Trends: uma no eixo principal relativa ao interesse por greves (StrikeAction) e outra no eixo secundário relativa ao interesse por sindicatos (Trade Union). Ao traçarmos linhas de tendência, percebemos que há uma tendência de declínio, na última década, do interesse por sindicatos (o que, de alguma forma, confirma a premissa da literatura de que os sindicatos estão perdendo influência). Notamos, também, entretanto, que há uma leve tendência de crescimento do interesse por greves.

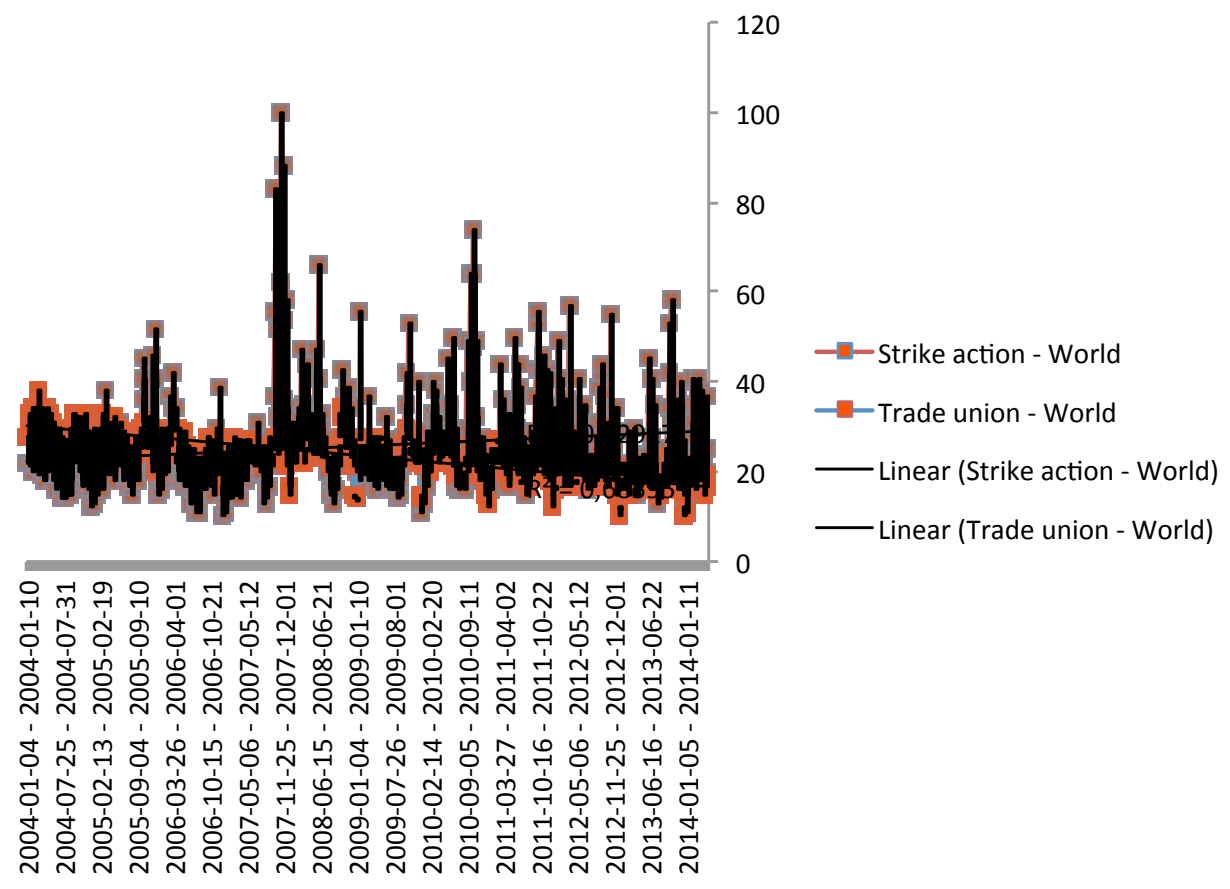

Gráfico 1- Interesse mundial por sindicatos e por greves (2004-2014)

Fonte: Google Trends, elaboração dos autores.

${ }^{11}$ Beta do Google Trends procura o termo como um "assunto". Podemos afirmar que isso faz desta frequência um forte medidor de ideologia política e de outras expressões do interesse social. 
Tabela 1 - Médias relativas às frequências temporais de interesse mundial por Trade Union e por StrikeAction*

\begin{tabular}{ccccccc}
\hline Grupo & Semanas & Média & CI 95\% & $\begin{array}{c}\text { Desvio } \\
\text { Padrão }\end{array}$ & Min & Max \\
\hline Trade_Union_-_World & 540 & 23.431 & $23.032-23.831$ & 4.741 & 10.0 & 38.0 \\
\hline Strike_Action_-_World & 540 & 25.757 & $24.807-26.708$ & 11.273 & 10.0 & 100.0 \\
\hline
\end{tabular}

Fonte: Google Trends, elaboração dos autores.

É interessante notar que a média de interesse mundial por estes dois tópicos é bastante similar, diferenciando-se apenas por 2,376 pontos. Considerando os valores mínimos e máximos para cada frequência, ambas se igualam quanto aos valores mínimos (10). Contudo, enquanto o tópico relacionado ao sindicato tem como frequência máxima 38 , o tópico relacionado às greves tem 100 como frequência máxima, indicando que o interesse por greves é mais explosivo, por assim dizer, que o interesse por sindicatos. Em função disso, o desvio padrão encontrado nas frequências é maior na frequência de interesse por greves. Percebemos aqui uma lógica funcional, afinal, dentre os que se interessam por greves, além dos grevistas, estão os usuários dos serviços em greve e outros atores sociais envolvidos. Isso também indica que nem sempre a greve é, cognitivamente, associada aos sindicatos, pois, se assim fosse, os valores máximos entre as frequências seriam coincidentes e não discrepantes.

Tabela 2 - Correlações entre as frequências temporais de interesse mundial por Trade Union e por StrikeAction

\begin{tabular}{llll}
\hline Pearson & Spearman's Test & T-Test & $\begin{array}{l}\text { Wilcoxon Signed Ranks } \\
\text { Test }\end{array}$ \\
\hline$p=0.141 ; r=0.063$ & $p=0.160 ; r=0.063$ & $p=<0.001 ; t=-4.523$ & $p=0.030 ; z=58865.0$ \\
\hline
\end{tabular}
Fonte: elaboração dos autores.

Ao correlacionar a frequência de interesse por greves e sindicatos no mundo ( $p=0.141 ; r=0.063$ ), não encontramos correlação significativa, confirmando a ideia de que nem sempre as greves são associadas a sindicatos e, muitas vezes, mesmo quando articuladas por sindicatos, não há uma percepção coletiva sobre este órgão.

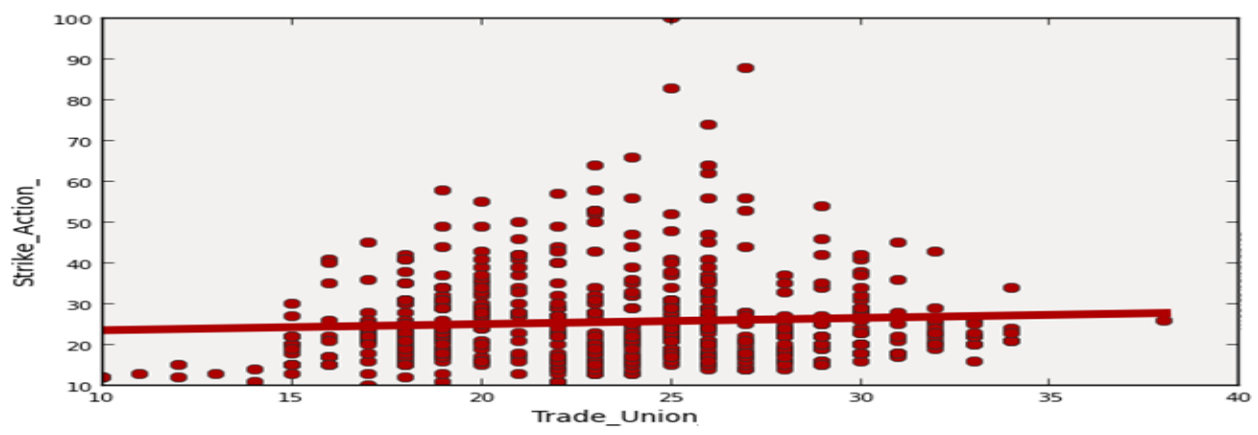

Gráfico 2 - Dispersão entre interesse por sindicatos e interesse por greves. Fonte: elaboração dos autores.

- Trade Union: Sindicatos; Strike Action: Greve. 
Tabela 3 - Qualidade da democracia e interesse pelos tópicos Trade Union e StrikeActionem 114 países

\begin{tabular}{|c|c|c|c|c|c|c|}
\hline País & $\begin{array}{l}2008-2009 \\
\text { Qualidade da } \\
\text { democracia }\end{array}$ & $\begin{array}{l}\text { 2011-2012 } \\
\text { Qualidade da } \\
\text { democracia }\end{array}$ & $\begin{array}{c}2008-2012 \text { - } \\
\text { média } \\
\text { Qualidade da } \\
\text { democracia }\end{array}$ & Trade Union & StrikeAction & $\begin{array}{c}\text { Média } \\
\text { 2004-2014 }\end{array}$ \\
\hline Albânia & 56 & 55,7 & 55,9 & 0 & 4 & 2 \\
\hline Argentina & 69,1 & 70,2 & 69,6 & 58 & 3 & 30,5 \\
\hline Armênia & 45 & 46,1 & 45,6 & 0 & 2 & 1 \\
\hline Austrália & 79,8 & 80,8 & 80,3 & 9 & 5 & 7 \\
\hline Áustria & 79,7 & 81,2 & 80,5 & 10 & 4 & 7 \\
\hline Bahrein & 42,4 & 39,4 & 40,9 & 0 & 3 & 1,5 \\
\hline Bangladesh & 47 & 49,3 & 48,1 & 3 & 3 & 3 \\
\hline Bélgica & 79,1 & 81,1 & 80,1 & 10 & 13 & 11,5 \\
\hline Benin & 47 & 49,3 & 48,1 & 0 & 37 & 18,5 \\
\hline Butão & 46,4 & 48,9 & 47,6 & 0 & 0 & 0 \\
\hline Bolívia & 53,8 & 56,1 & 54,9 & 10 & 3 & 6,5 \\
\hline $\begin{array}{c}\text { Bósnia e } \\
\text { Herzegovina }\end{array}$ & 49,6 & 50,2 & 49,9 & 16 & 6 & 11 \\
\hline Botswana & 52,3 & 52,3 & 52,3 & 21 & 16 & 18,5 \\
\hline Brasil & 61,1 & 63,8 & 62,5 & 100 & 28 & 64 \\
\hline Bulgária & 65,1 & 65,1 & 65,1 & 2 & 3 & 2,5 \\
\hline Burkina Faso & 41 & 43,1 & 42,1 & 0 & 16 & 8 \\
\hline Burundi & 41,1 & 39,5 & 40,3 & 0 & 0 & 0 \\
\hline Canadá & 79,8 & 80,6 & 80,2 & 12 & 13 & 12,5 \\
\hline $\begin{array}{c}\text { República Centro } \\
\text {-Africana }\end{array}$ & 30,4 & 31 & 30,7 & 0 & 0 & 0 \\
\hline Chile & 71,3 & 71,9 & 71,6 & 18 & 5 & 11,5 \\
\hline China & 38,4 & 39,1 & 38,7 & 20 & 3 & 11,5 \\
\hline Colômbia & 55,8 & 57,5 & 56,6 & 12 & 2 & 7 \\
\hline Costa Rica & 70 & 71,1 & 70,6 & 7 & 4 & 5,5 \\
\hline Croácia & 67,5 & 68 & 67,8 & 28 & 4 & 16 \\
\hline Chipre & 72 & 71,5 & 71,8 & 3 & 6 & 4,5 \\
\hline $\begin{array}{l}\text { República } \\
\text { Tcheca }\end{array}$ & 72,1 & 71,9 & 72 & 5 & 3 & 4 \\
\hline Dinamarca & 83,9 & 84,4 & 84,1 & 23 & 18 & 20,5 \\
\hline $\begin{array}{l}\text { República } \\
\text { Dominicana }\end{array}$ & 59,4 & 58,9 & 59,2 & 7 & 5 & 6 \\
\hline Equador & 58,2 & 57,9 & 58,1 & 12 & 2 & 7 \\
\hline Egito & 35,1 & 41,2 & 38,2 & 0 & 5 & 2,5 \\
\hline El Salvador & 59,1 & 60,1 & 59,6 & 16 & 3 & 9,5 \\
\hline Estônia & 73,3 & 73,2 & 73,2 & 2 & 4 & 3 \\
\hline Finlândia & 86 & 86,7 & 86,4 & 8 & 6 & 7 \\
\hline França & 77,2 & 78,2 & 77,7 & 4 & 21 & 12,5 \\
\hline Geórgia & 52,7 & 57,1 & 54,9 & 0 & 4 & 2 \\
\hline Alemanha & 81,1 & 82,2 & 81,6 & 7 & 11 & 9 \\
\hline Gana & 54 & 55,5 & 54,8 & 8 & 7 & 7,5 \\
\hline Grécia & 69,9 & 67,5 & 68,7 & 1 & 49 & 25 \\
\hline Guatemala & 50,2 & 51,2 & 50,7 & 11 & 5 & 8 \\
\hline Guiné & 28,5 & 36,2 & 32,4 & 0 & 0 & 0 \\
\hline Haiti & 40,3 & 40,2 & 40,3 & 0 & 0 & 0 \\
\hline Honduras & 51,3 & 50 & 50,6 & 13 & 7 & 10 \\
\hline Hungria & 70 & 68,4 & 69,2 & 5 & 6 & 5,5 \\
\hline Índia & 52,3 & 54,1 & 53,2 & 4 & 6 & 5 \\
\hline Indonésia & 52,4 & 54,2 & 53,3 & 3 & 2 & 2,5 \\
\hline
\end{tabular}


(continuação...)

\begin{tabular}{|c|c|c|c|c|c|c|}
\hline País & \begin{tabular}{|c|}
$2008-2009$ \\
Qualidade da \\
democracia
\end{tabular} & $\begin{array}{c}\text { 2011-2012 } \\
\text { Qualidade da } \\
\text { democracia }\end{array}$ & $\begin{array}{c}\text { 2008-2012 - } \\
\text { média } \\
\text { Qualidade da } \\
\text { democracia }\end{array}$ & Trade Union & StrikeAction & $\begin{array}{c}\text { Média } \\
\text { 2004-2014 }\end{array}$ \\
\hline Irlanda & 81,4 & 80,9 & 81,1 & 8 & 7 & 7,5 \\
\hline Israel & 73,6 & 73,7 & 73,7 & 5 & 12 & 8,5 \\
\hline Itália & 71,8 & 71,2 & 71,5 & 22 & 37 & 29,5 \\
\hline Jamaica & 65,2 & 65,9 & 65,6 & 16 & 3 & 9,5 \\
\hline Japão & 74,6 & 74,8 & 74,7 & 9 & 2 & 5,5 \\
\hline Quênia & 41 & 44,8 & 42,9 & 12 & 17 & 14,5 \\
\hline Coreia do Sul & 70,7 & 71,7 & 71,2 & 0 & 0 & 0 \\
\hline Kuwait & 49,9 & 49,3 & 49,6 & 0 & 3 & 1,5 \\
\hline $\begin{array}{l}\text { República do } \\
\text { Quirguizistão }\end{array}$ & 43,8 & 46,4 & 45,1 & 0 & 0 & 0 \\
\hline Letônia & 69,8 & 69,3 & 69,6 & 1 & 4 & 2,5 \\
\hline Líbano & 49,5 & 50,2 & 49,8 & 3 & 6 & 4,5 \\
\hline Lesoto & 50,9 & 53,8 & 52,4 & 0 & 0 & 0 \\
\hline Libéria & 49,3 & 52 & 50,7 & 0 & 0 & 0 \\
\hline Líbia & 25,9 & 38,9 & 32,4 & 0 & 2 & 1 \\
\hline Lituânia & 71,1 & 71,3 & 71,2 & 1 & 3 & 2 \\
\hline Macedônia, FYR & 53,3 & 54,6 & 53,9 & 4 & 5 & 4,5 \\
\hline Madagascar & 45,4 & 42,8 & 44,1 & 0 & 6 & 3 \\
\hline Malawi & 44,2 & 47,4 & 45,8 & 0 & 0 & 0 \\
\hline Malásia & 51,3 & 52 & 51,6 & 3 & 3 & 3 \\
\hline Maurício & 65,4 & 66,4 & 65,9 & 7 & 5 & 6 \\
\hline México & 57,6 & 57,7 & 57,6 & 19 & 5 & 12 \\
\hline Moldávia & 54,4 & 57,8 & 56,1 & 3 & 3 & 3 \\
\hline Mongólia & 58 & 59,6 & 58,8 & 0 & 4 & 2 \\
\hline Marrocos & 43,5 & 44,6 & 44,1 & 1 & 7 & 4 \\
\hline Moçambique & 42,3 & 43,2 & 42,7 & 10 & 12 & 11 \\
\hline Namíbia & 53,1 & 54,4 & 53,7 & 0 & 8 & 4 \\
\hline Nepal & 46,8 & 47,2 & 47 & 5 & 6 & 5,5 \\
\hline Países Baixos & 82,9 & 83,5 & 83,2 & 0 & 0 & 0 \\
\hline Nova Zelândia & 81,8 & 81,5 & 81,6 & 5 & 4 & 4,5 \\
\hline Nicarágua & 52,4 & 53,7 & 53,1 & 9 & 3 & 6 \\
\hline Nigéria & 36,8 & 38,7 & 37,8 & 13 & 100 & 56,5 \\
\hline Noruega & 87,4 & 88,3 & 87,9 & 6 & 10 & 8 \\
\hline Paquistão & 37,1 & 38,2 & 37,6 & 2 & 4 & 3 \\
\hline Panamá & 64,7 & 65,8 & 65,2 & 9 & 4 & 6,5 \\
\hline $\begin{array}{l}\text { Papua-Nova } \\
\text { Guiné }\end{array}$ & 51,3 & 52,2 & 51,8 & 0 & 0 & 0 \\
\hline Paraguai & 54,1 & 53,9 & 54 & 8 & 8 & 8 \\
\hline Peru & 61,7 & 61 & 61,3 & 10 & 8 & 9 \\
\hline Filipinas & 54 & 57,3 & 55,7 & 0 & 0 & 0 \\
\hline Polônia & 70,3 & 71,1 & 70,7 & 7 & 4 & 5,5 \\
\hline Portugal & 75,3 & 75,7 & 75,5 & 28 & 18 & 23 \\
\hline Romênia & 63,7 & 64,4 & 64,1 & 4 & 6 & 5 \\
\hline Panamá & 64,7 & 65,8 & 65,2 & 9 & 4 & 6,5 \\
\hline $\begin{array}{l}\text { Papua-Nova } \\
\text { Guiné }\end{array}$ & 51,3 & 52,2 & 51,8 & 0 & 0 & 0 \\
\hline Paraguai & 54,1 & 53,9 & 54 & 8 & 8 & 8 \\
\hline Peru & 61,7 & 61 & 61,3 & 10 & 8 & 9 \\
\hline Filipinas & 54 & 57,3 & 55,7 & 0 & 0 & 0 \\
\hline Polônia & 70,3 & 71,1 & 70,7 & 7 & 4 & 5,5 \\
\hline
\end{tabular}

(continua...) 
(continuação...)

\begin{tabular}{|c|c|c|c|c|c|c|}
\hline País & $\begin{array}{c}2008-2009 \\
\text { Qualidade da } \\
\text { democracia }\end{array}$ & $\begin{array}{c}2011-2012 \\
\text { Qualidade da } \\
\text { democracia }\end{array}$ & $\begin{array}{c}\text { 2008-2012 - } \\
\text { média } \\
\text { Qualidade da } \\
\text { democracia }\end{array}$ & Trade Union & StrikeAction & $\begin{array}{c}\text { Média } \\
\text { 2004-2014 }\end{array}$ \\
\hline Portugal & 75,3 & 75,7 & 75,5 & 28 & 18 & 23 \\
\hline Romênia & 63,7 & 64,4 & 64,1 & 4 & 6 & 5 \\
\hline Panamá & 64,7 & 65,8 & 65,2 & 9 & 4 & 6,5 \\
\hline $\begin{array}{c}\text { Papua-Nova } \\
\text { Guiné }\end{array}$ & 51,3 & 52,2 & 51,8 & 0 & 0 & 0 \\
\hline Paraguai & 54,1 & 53,9 & 54 & 8 & 8 & 8 \\
\hline Peru & 61,7 & 61 & 61,3 & 10 & 8 & 9 \\
\hline Filipinas & 54 & 57,3 & 55,7 & 0 & 0 & 0 \\
\hline Polônia & 70,3 & 71,1 & 70,7 & 7 & 4 & 5,5 \\
\hline Portugal & 75,3 & 75,7 & 75,5 & 28 & 18 & 23 \\
\hline Romênia & 63,7 & 64,4 & 64,1 & 4 & 6 & 5 \\
\hline Panamá & 64,7 & 65,8 & 65,2 & 9 & 4 & 6,5 \\
\hline $\begin{array}{c}\text { Papua-Nova } \\
\text { Guiné }\end{array}$ & 51,3 & 52,2 & 51,8 & 0 & 0 & 0 \\
\hline Paraguai & 54,1 & 53,9 & 54 & 8 & 8 & 8 \\
\hline Peru & 61,7 & 61 & 61,3 & 10 & 8 & 9 \\
\hline Filipinas & 54 & 57,3 & 55,7 & 0 & 0 & 0 \\
\hline Polônia & 70,3 & 71,1 & 70,7 & 7 & 4 & 5,5 \\
\hline Portugal & 75,3 & 75,7 & 75,5 & 28 & 18 & 23 \\
\hline Romênia & 63,7 & 64,4 & 64,1 & 4 & 6 & 5 \\
\hline Federação Russa & 45 & 45,8 & 45,4 & 5 & 2 & 3,5 \\
\hline Senegal & 48,5 & 50,8 & 49,6 & 0 & 7 & 3,5 \\
\hline $\begin{array}{c}\text { Sérvia e Monte- } \\
\text { negro }\end{array}$ & 60,4 & 61,4 & 60,9 & 34 & 8 & 21 \\
\hline Serra Leoa & 44,5 & 47,6 & 46 & 0 & 0 & 0 \\
\hline Cingapura & 64 & 66,9 & 65,4 & 4 & 6 & 5 \\
\hline $\begin{array}{c}\text { República } \\
\text { Eslovaca }\end{array}$ & 68,8 & 69,2 & 69 & 7 & 5 & 6 \\
\hline Eslovênia & 75,2 & 75,4 & 75,3 & 16 & 4 & 10 \\
\hline África do Sul & 55,2 & 55,1 & 55,1 & 21 & 16 & 18,5 \\
\hline Espanha & 77,9 & 76,9 & 77,4 & 31 & 17 & 24 \\
\hline Sri Lanka & 52,3 & 49,8 & 51 & 4 & 4 & 4 \\
\hline Suécia & 86,9 & 87 & 87 & 9 & 6 & 7,5 \\
\hline Suíça & 84,9 & 85,9 & 85,4 & 5 & 5 & 5 \\
\hline $\begin{array}{c}\text { República Árabe } \\
\text { da Síria }\end{array}$ & 31,3 & 29,2 & 30,2 & 0 & 3 & 1,5 \\
\hline Tanzânia & 43 & 47 & 45 & 8 & 3 & 5,5 \\
\hline Tailândia & 51,2 & 54,2 & 52,7 & 0 & 1 & 0,5 \\
\hline Timor-Leste & 50,4 & 51,3 & 50,8 & 0 & 0 & 0 \\
\hline Togo & 33,4 & 35,8 & 34,6 & 0 & 0 & 0 \\
\hline Trinidad e Tobago & 61,1 & 60,1 & 60,6 & 14 & 3 & 8,5 \\
\hline Tunísia & 38,7 & 52,3 & 45,5 & 1 & 8 & 4,5 \\
\hline Turquia & 53,8 & 54,9 & 54,3 & 12 & 2 & 7 \\
\hline Uganda & 45,1 & 45,9 & 45,5 & 10 & 6 & 8 \\
\hline Ucrânia & 57,3 & 54,5 & 55,9 & 6 & 2 & 4 \\
\hline Reino Unido & 80,1 & 79,9 & 80 & 10 & 13 & 11,5 \\
\hline Estados Unidos & 78,7 & 78,8 & 78,7 & 11 & 7 & 9 \\
\hline Uruguai & 72,1 & 73 & 72,6 & 18 & 3 & 10,5 \\
\hline Venezuela, RB & 48,8 & 46,1 & 47,5 & 12 & 3 & 7,5 \\
\hline Iêmen & 25,7 & 26,5 & 26,1 & 0 & 3 & 1,5 \\
\hline Zâmbia & 39,8 & 44,4 & 42,1 & 17 & 0 & 8,5 \\
\hline
\end{tabular}

Fonte: Google Trends, The Democracy Ranking Association, elaboração dos autores. 
Tabela 4 - Qualidade da democracia e interesse pelos tópicos Trade Union e StrikeAction em 114 países

\begin{tabular}{ccccccc}
\hline Grupo & Países & Média & CI 95\% & $\begin{array}{c}\text { Desvio } \\
\text { Padrão }\end{array}$ & Mín. & Máx. \\
\hline $\begin{array}{c}\text { Média Google Trends } \\
\text { 2004-2014 }\end{array}$ & 114 & 7.746 & $6.004-9.487$ & 9.488 & 0.0 & 64.0 \\
\hline $\begin{array}{c}\text { 2008-2012 - Média Qualidade da } \\
\text { Democracia }\end{array}$ & 114 & 58.438 & $55.711-61.164$ & 14.853 & 26.1 & 87.9 \\
\hline $\begin{array}{c}\text { 2008-2009 } \\
\text { Qualidade da Democracia }\end{array}$ & 114 & 57.887 & $55.091-60.683$ & 15.232 & 25.7 & 87.4 \\
\hline $\begin{array}{c}\text { 2011-2012 Qualidade da Demo- } \\
\text { cracia }\end{array}$ & 114 & 58.989 & $56.317-61.661$ & 14.556 & 26.5 & 88.3 \\
\hline $\begin{array}{c}\text { Trade Union } \\
\text { Strike Action }\end{array}$ & 114 & 8.36 & $6.077-10.642$ & 12.435 & 0.0 & 100 \\
\hline
\end{tabular}

Fonte: elaboração dos autores.

É possível observar que, entre o período de 2008-2009 até o período de 2011-2012, a média da qualidade da democracia nos 114 países analisados teve um leve aumento de 1,102 pontos, o que podemos considerar como um saldo positivo. É interessante notar, também, que, quanto aos valores mínimos e máximos relativos à média da qualidade da democracia, há uma grande discrepância entre o país com menor pontuação (26,1 pontos) e o com maior pontuação ( 87,9 pontos). Este resultado sinaliza que há uma grande desigualdade estrutural no mundo, a qual faz com que, assim como os recursos, os direitos sociais, políticos e econômicos sejam distribuídos de forma desigual. 


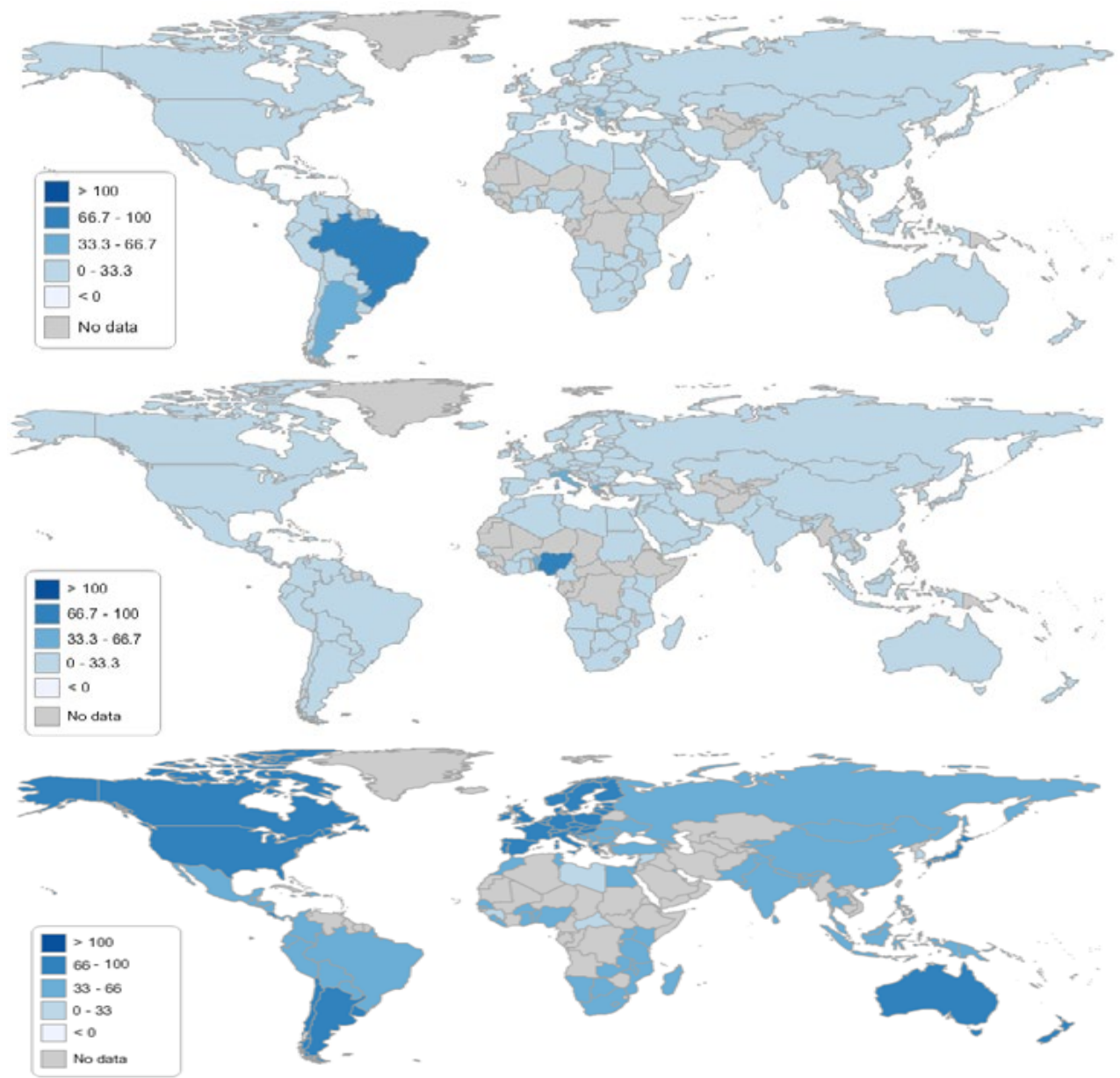

Figura 1 - Distribuição mundial de interesse por tópicos ligados a sindicatos e greves e as pontuações relativas à qualidade da democracia em 114 países.

Fonte: Google Trends, The Democracy Ranking Association, elaboração dos autores.

Tabela 5 - Correlações entre as médias de frequências do Google Trends e a média de qualidade da democracia em 114 países

\begin{tabular}{cccc}
\hline Pearson & Spearman's Test & t-test & $\begin{array}{c}\text { Wilcoxon Signed } \\
\text { Ranks Test }\end{array}$ \\
\hline$p=: 0.036 ; r=0.197$ & $p=<0.001 ; r=0.197$ & $p=<0.001 ; t=-33.878$ & $p=<0.001 ; z=3.0$ \\
\hline
\end{tabular}

Fonte: elaboração dos autores. 
Como fica evidente no Gráfico 3 e na Tabela 6 , há uma correlação positiva $(p=: 0.036 ; r=0.197)$ entre a qualidade da democracia e a média de interesse por tópicos relacionados a sindicatos e greves trabalhistas. Isso indica que, em democracias de maior qualidade, os indivíduos têm, ou pelo menos demonstram ter, maior interesse por sindicatos e por greves trabalhistas como um todo, sinalizando que não só são livres para se organizar em sindicatos e também promover greves, mas também estão culturalmente interessados neste tipo de temática, mais do que os indivíduos situados em democracias de menor qualidade.

Tal resultado pode indicar que, nos lugares onde $\mathrm{o}$ interesse por greves $\mathrm{e}$ por sindicatos é maior, os sindicatos são mais "fortes" e que sua representação exerce significativo efeito para garantir uma considerável fatia das demandas para o melhoramento da qualidade da democracia. Nesse sentido, podemos afirmar que o interesse médio por greves e por sindicatos representa tanto uma causa quanto uma consequência da qualidade da democracia.

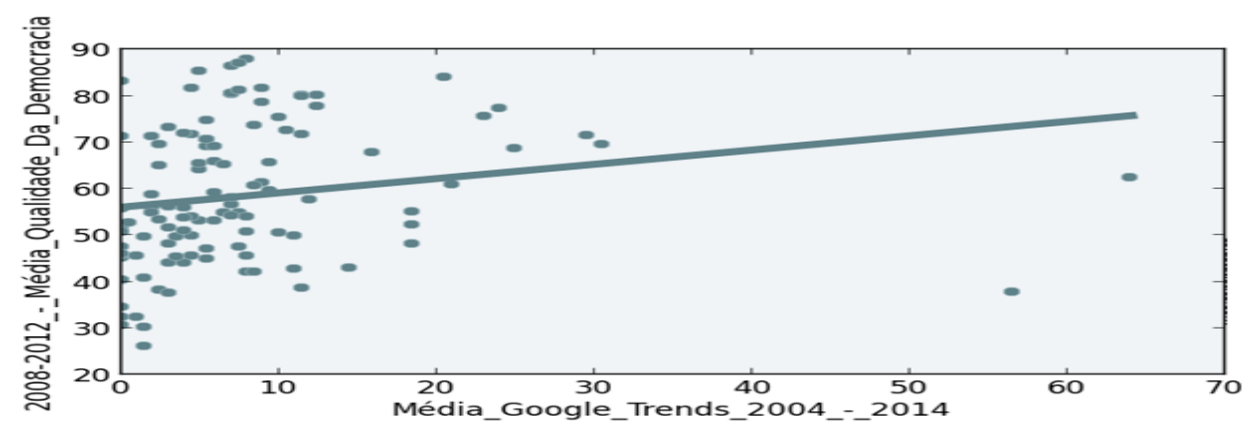

Gráfico 3 - Dispersão entre a média da qualidade da democracia (2008-2012) e a média da distribuição geográfica de interesse por sindicatos e greves (2004-2012).

Fonte: elaboração dos autores.

No Gráfico 4, apresentado a seguir, ilustramos a relação quanto à distribuição em 114 países do interesse médio por sindicatos e greves e comparamos esta relação com a distribuição de pontos relativos à qualidade da democracia. Fica evidente que tal média de interesse mensurada pelo Google Trends, de fato, é mais recorrente em democracias com pontuação mais elevada quanto à qualidade.

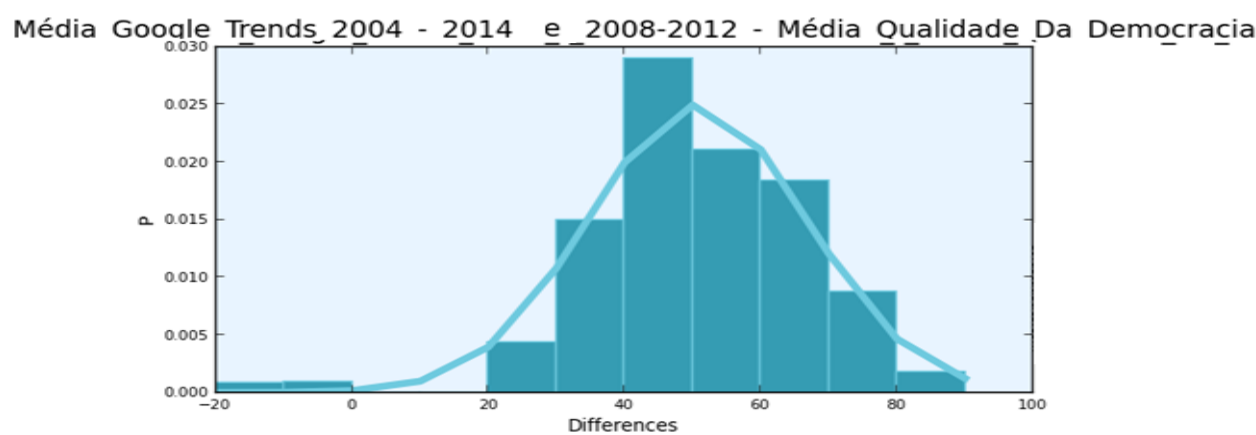

Gráfico 4 - Comparação do padrão de distribuição média da qualidade da democracia (20082012) e da média de distribuição geográfica de interesse por sindicatos e greves (2004-2012) Fonte: elaboração dos autores. 
Para estudar melhor a relação entre a distribuição geográfica de interesse por greves e sindicatos com a qualidade da democracia, comparamos a distribuição de greves e de sindicatos de forma separada com a média de qualidade da democracia. Observamos um padrão bastante interessante, pois os valores de correlação de Pearson para o tópico ligado a greves não apresentam correlação significativa ( $p=: 0.511$; $r=0.062$ ), enquanto que a distribuição de interesse por sindicatos apresenta uma forte correlação positiva ( $p=0.010$; $r=0.242$ ). Tendo isso em vista, realizamos uma regressão linear considerando como variável dependente a média da distribuição geográfica da qualidade da democracia entre 2008 e 2012 e como variável independente a distribuição do interesse médio no mesmo período por sindicatos.

Tabela 6 - Resumo do modelo / ANOVA ${ }^{\mathrm{a}} /$ Coeficientes $^{\mathrm{a}}$

\begin{tabular}{|c|c|c|c|c|c|c|}
\hline & Modelo & $\mathbf{R}$ & $\begin{array}{c}\mathbf{R} \\
\text { quadrado }\end{array}$ & $\begin{array}{c}\text { R quadrado } \\
\text { ajustado }\end{array}$ & \multicolumn{2}{|c|}{$\begin{array}{c}\text { Erro padrão } \\
\text { da estimativa }\end{array}$} \\
\hline & 1 & $242^{\mathrm{a}}$ & ,058 & ,050 & \multicolumn{2}{|c|}{12,120} \\
\hline & Modelo & Soma dos Quadrados & df & Quadrado Médio & $\mathbf{F}$ & Sig. \\
\hline \multirow{3}{*}{1} & Regressão & 1020,248 & 1 & 1020,248 & 6,946 &, $010^{\mathrm{b}}$ \\
\hline & Resíduos & 16452,006 & 112 & 146,893 & & \\
\hline & Total & 17472,254 & 113 & & & \\
\hline \multirow{2}{*}{\multicolumn{2}{|c|}{ Modelo }} & \multicolumn{2}{|c|}{$\begin{array}{c}\text { Coeficientes } \\
\text { não padronizados }\end{array}$} & $\begin{array}{c}\text { Coeficientes } \\
\text { padronizados }\end{array}$ & \multirow[t]{2}{*}{$\mathbf{t}$} & \multirow[t]{2}{*}{ Sig. } \\
\hline & & $\mathbf{B}$ & $\begin{array}{l}\text { Modelo } \\
\text { padrão }\end{array}$ & Beta & & \\
\hline \multirow{3}{*}{1} & (Constante) & 6,519 & 1,333 & & 4,891 &, 000 \\
\hline & $\begin{array}{l}\text { Sindicatos_Goo- } \\
\text { gle_Trends }\end{array}$ & ,258 & ,098 & ,242 & 2,635 & ,010 \\
\hline & & & & & & \\
\hline \multicolumn{7}{|c|}{ a. Variável dependente: Média_qualidade_da_democracia_2008_2012 } \\
\hline \multicolumn{7}{|c|}{ b.Preditores: (Constante), Sindicatos_Google_Trends } \\
\hline
\end{tabular}

Fonte: elaboração dos autores.

Como visualizamos na regressão, obtemos um r quadrado ajustado de , 050 , o que indica que $5 \%$ da distribuição da qualidade de democracia pode ser explicada pelo interesse popular por sindicatos. De um lado, isso sugere que, em países com menor qualidade democrática, pode ser mais frequente o interesse por greves. Assim, as disparidades estruturais advindas da baixa qualidade da democracia podem ter colocado em curso greves que, por sua vez, geraram o interesse nos motores de busca do Google. Por outro lado, não deixa dúvidas de que o interesse por sindicatos é mais frequente em democracias de maior qualidade, o que pode indicar que as greves estão reduzindo quanto à sua frequência nas democracias de maior qualidade.
Mas, como consideramos que o interesse médio no Google Trends por sindicatos, em alguma medida, representa um indicador de força, pode ser que esta discrepância em relação ao interesse por greves represente uma tendência mundial quanto à postura estratégica e operacional dos sindicatos. Ou seja, os sindicatos podem estar se adequando e conseguindo meios alternativos para exercer pressão sobre o poder político a fim de representar com mais força os trabalhadores sindicalizados e com menos força os não sindicalizados. 

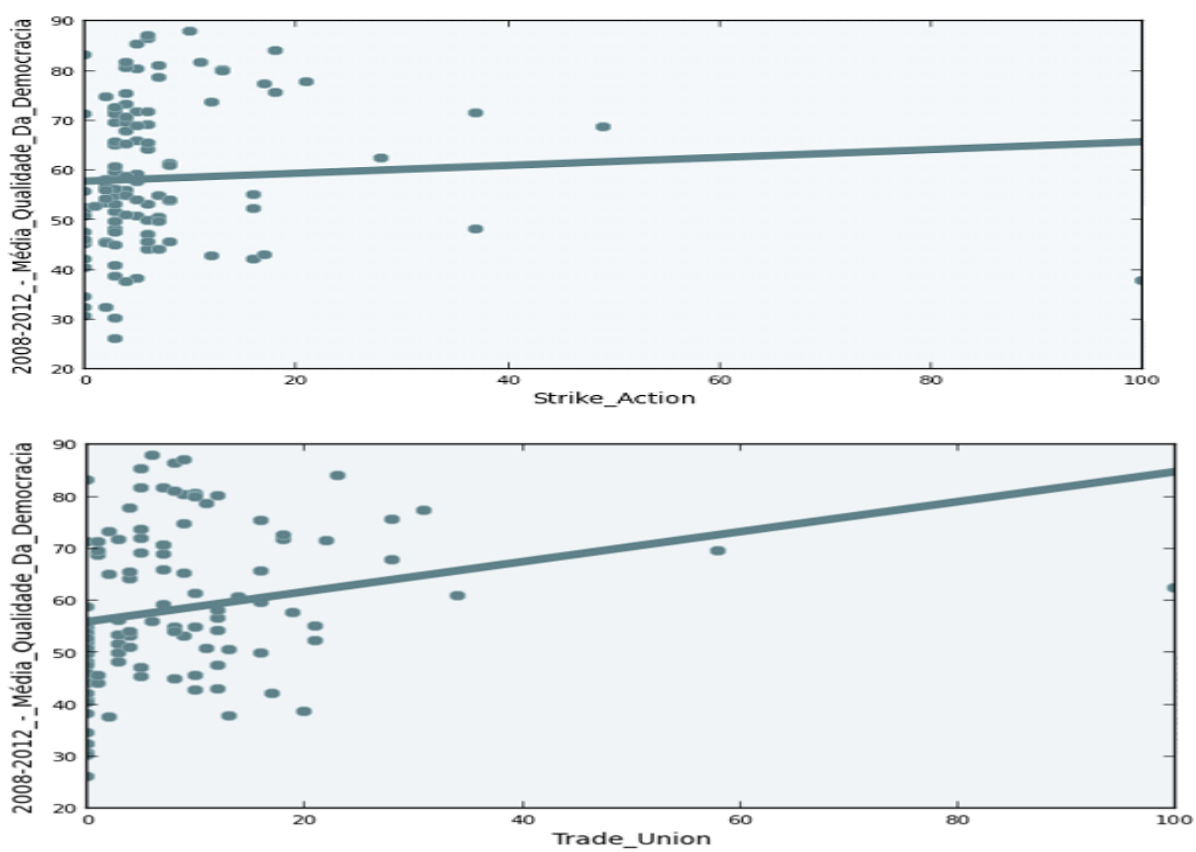

Gráfico 5 - Dispersões entre a média da qualidade da democracia e a tendência de interesse por greves e por sindicatos no Google Trends Fonte: elaboração dos autores.

Nossos resultados indicam que entre o interesse por sindicatos e greves não há correlação significativa, o que mostra que nem sempre as greves são associadas aos sindicatos. Ao compararmos a média total quanto à distribuição geográfica do interesse por greves e sindicatos, constatamos uma significativa correlação que indica que o interesse por sindicatos é maior em países mais democráticos. Todavia, ao compararmos separadamente a distribuição do interesse por greves e sindicatos com a qualidade da democracia, constatamos que há uma forte correlação $(r=0.242$, $p=0.010$ ) entre o interesse por greves e a democracia, o que não se repete quanto ao interesse por sindicatos $(r=0.062$, $p=0.511$ ). Podemos afirmar, ainda, que uma taxa de $5 \%$ da distribuição geográfica da qualidade da democracia de 2008 a 2012 pode ser explicada pelo interesse popular por sindicatos. Isso confirma nossa segunda hipótese, podendo indicar, também, que os sindicatos estão adotando outras estratégias além das greves, motivo pelo qual é possível inferir que os sindicatos vão "sobreviver" à tendência atual de perda de densidade. Contudo, verificamos, em uma avaliação temporal do interesse por sindicatos, uma tendência de declínio no volume de buscas, o que confirma a tendência prevista na literatura relacionada à diminuição de influência desses órgãos.

\section{Considerações Finais}

Nosso primeiro resultado mostra que não existe significativa correlação entre o interesse por greves e o interesse por sindicatos, o que indica que nem sempre as greves estão e/ou são $\operatorname{cog}$ nitivamente associadas aos sindicatos. Tendo isso em vista, nossa primeira hipótese parece ser verdadeira, já que, ao compararmos a média conjunta do interesse por greves e sindicatos com a média da qualidade da democracia, encontramos uma forte correlação positiva, indicando que este tipo de frequência de interesse é mais comum em países mais democráticos. Tal achado pode apontar 
para o fato de que, em países onde esse tipo de frequência é alta, as pessoas são mais engajadas aos sindicatos, conferindo, consequentemente, mais poder a essa instituição para que represente os envolvidos. Nesse caso, parte da representação tende a impactar de forma positiva a qualidade da democracia.

Todavia, ao comparar separadamente o interesse por sindicatos e greves com a qualidade da democracia, constatamos que em relação ao primeiro há uma forte correlação ( $p=0.010$; $r=0.242$ ) entre $\mathrm{o}$ interesse por sindicatos e a qualidade da democracia, o que não se verifica em relação ao interesse por greves $(p=: 0.511 ; r=0.062$ ). Podemos afirmar, assim, que 5\% da distribuição geográfica da qualidade da democracia,

\section{Referências}

1. ADDISON, J. The consequences of trade union power erosion. British Journal of Industrial Relations, no prelo, 2013.

2. ANDOLFATTO, D.; LABBÉ, D. The Future of the French Trade Unions. Management Revue, p. 341-352, 2012.

3. AZMAT, G.; MANNING, A.; REENEN, J. V. Privatization and the Decline of Labour's Share: International Evidence from Network Industries. Economica, v. 79, n. 315, p. 470-492, 2012.

4. CAMPBELL, D. FJ. The basic concept for the democracy ranking of the quality of democracy. Vienna: Democracy Ranking, 2008.

5. DONADO, A.; WÄLDE, K. How Trade Unions Increase Welfare.Universitécatholique de Louvain, Institut de RecherchesEconomiquesetSociales (IRES), 2010.

6. FANTAZZINI, D.; FOMICHEV, N. Forecasting the real price of oil using online search data. International Journal of Computational Economics and Econometrics, v. 4, n. 1, p. 4-31, 2014. entre 2008 e 2012, pode ser explicada pelo interesse popular em sindicatos. Isso confirma nossa segunda hipótese, podendo indicar, também, que os sindicatos estão adotando outras estratégias além das greves. Esse resultado sugere que os sindicatos, possivelmente, vão "sobreviver" à tendência atual de perda de densidade. De toda forma, essa perda de densidade e influência, prevista na literatura, é corroborada pela tendência temporal de interesse por sindicatos, que segue em declínio.

Em futuros estudos, é interessante que se compare a frequência de interesse por sindicatos no mundo com a densidade dos sindicatos, a fim de conferir se, de fato, onde o interesse por sindicatos é maior, estes órgãos são mais fortes.

7. GOERKE, L.; PANNENBERG, $M$. Trade union membership and sickness absence: Evidence from a sick pay reform. CESifo Working $\mathrm{Pa}-$ per: Social Protection, 2012.

8. HAYTER, S.; FASHOYIN, T.; KOCHAN, T. A. Review essay: Collective bargaining for the 21 st century. Journal of Industrial Relations, v. 53, n. 2, p. 225-247, 2011.

9. KARABARBOUNIS, L.; NEIMAN, B. The global decline of the labor share. The Quarterly Journal of Economics, v. 129, n. 1, p. 61-103, 2014.

10. KUO, C.-T. et al. An Analysis of Security Patch Lifecycle Using Google Trend Tool. In: Information Security (Asia JCIS), 2012 Seventh Asia Joint Conference on. IEEE, 2012. p. 31-34.

11. MELLON, J. Where and When Can We Use Google Trends to Measure Issue Salience?. PS: Political Science \& Politics, v. 46, n. 02, p. 280-290, 2013.

12. MORAES, T. P. B. et al. Mulheres, política e sub-representação. Um estudo sobre a correlação entre qualidade da democracia, ideologia e mulheres nos parlamentos. Revista Derecho y Cambio Social, n.36, p. 1-29, 2014. 
13. MORAES, T. P. B.; MAIA, S. P. A. Jornalismo na web e clonagem biológica: Um estudo sobre o tema clonagem nos cadernos de ciência online dos jornais O Estado de São Paulo e Folha de São Paulo. Aurora. Revista de Arte, Mídia e Política. ISSN 1982-6672, v. 7, n. 19, p. 71-96, 2014.

14. MORAES, T. P. B.; SANTOS, R. M. Os Protestos no Brasil. Um estudo sobre as pesquisas na web, e o caso da Primavera Brasileira. Revista Internacional de Investigación em Ciencias Sociales, v. 9, n. 2, p. 193-206, 2013.

15. MORAES, T. P. B.; MILLANI, F. Consumo Conspícuo e Racionalidade Limitada. Uma Crítica à Teoria da Escolha Racional a Partir da Psicologia Evolucionista. UNOPAR Científica Ciências Humanas e Educação, v. 15, n. 2, 2014.
16. MORAES, T. P. B.. Psicología social como una rama de especialización de labiología. Una muestra Del interes por psicología evolutiva a través del índice de búsqueda de google. Revista de Sociales y Jurídicas, n. 10, p. 6-126, 2014.

17. MORAES, T. P. B.; SANTOS, R. M. Caza al terrorismo y corrida electoral-un análisis sobre el impacto del interés regional por la muerte de Osama bin Laden y su relación con los votos en las elecciones presidenciales de 2012 en Estados Unidos. Revista PRISMA. COM, n. 27, 2015.

18. OLSON, M. A lógica da ação coletiva. Edusp, São Paulo, 1999.

19. TSEBELIS, G. Jogos ocultos. Edusp, São Paulo, 1998. 